\section{Research Square}

Preprints are preliminary reports that have not undergone peer review.

They should not be considered conclusive, used to inform clinical practice, or referenced by the media as validated information.

\title{
Relationship Between Loneliness and Internet Addiction: Testing of Serial Mediation and Moderated Mediation Models of Interpersonal Problems and Motivation for Internet Use
}

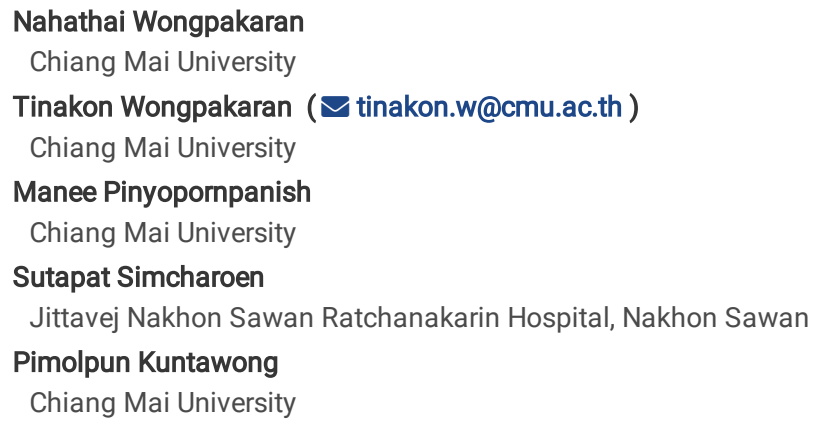




\section{Abstract \\ Background}

In the era of high-speed internet, using the internet regardless of platform might be considered a part of everyone's daily activities. A number of factors have been demonstrated to be associated with internet addiction, which is mostly concerned with psychological problems such as loneliness. This study aimed to examine how and in what way loneliness has influenced internet addiction. Specifically, we proposed and tested interpersonal problems and motivation for the internet as intervening variables of the relationship between loneliness and internet addiction.

\section{Methods}

Self-report measurement on loneliness, internet addiction test (IAT) and interpersonal problems consisting of domineering, vindictive, cold, socially inhibited, nonassertive, overly accommodating, self-sacrificing and intrusive, were administered to 318 medical students (57\% females); mean age was 20.88 (SD, 1.8 ), to test whether interpersonal problems mediated the relationship between loneliness and internet addiction in the mediation model. In addition, motivation for internet use was added to the mediation model and tested whether it was the second mediator (serial mediation model) or a moderator (moderated mediation model).

\section{Results}

After controlling for sex and age, socially inhibited problems exhibited full mediation whereas the remainder had partial mediation effect, with the exception that intrusive and cold interpersonal problems had no mediating role. Negative motivation and motivation for being accepted had mediation effects for all styles of interpersonal problems. Motivation for working was found to be a significant mediator and moderator of the most interpersonal problems. Intrusive and cold styles became a mediator only when some motivation variables were added to the model, implying that not only psychological problems should be included when analysis internet addiction, but also other variables such motivation for internet use. The percent of variance explained, by IAT score, increased from $13 \%$ by the mediation model to $33 \%$ by the moderated mediation model, and $43 \%$ by the serial mediation model.

\section{Conclusion}

The study suggested the crucial role of loneliness and interpersonal problems on internet addiction, for which motivation for the internet use explained how each interpersonal problem would be associated. This may provide some insight regarding the pathological characteristics of those using the internet as a coping strategy. Intervention to help students experiencing loneliness to avoid excessive use of the internet is possible when their interpersonal problems and various types of motivation are identified.

\section{Background}

Loneliness is common state of emotion that occurs across lifespan, and is linked to many physical, mental or behavioral problems,[1] especially internet addiction among adolescents or young adults.[2-5] Loneliness can have either a direct or indirect effect on internet addiction. Researchers have found that it could be mediated by shyness, family support, self-esteem, social anxiety, depression and interpersonal problems in rendering internet addiction.[6-13] Evidently, the relationship between loneliness and interpersonal problems exists, no study; however, has examined the entire aspect of interpersonal problems, especially in association with internet addiction.

Interpersonal problems, based on interpersonal circumplex, are categorized along two intersecting dimensions of affiliation axis (hostile versus friendly), and control axis (dominance versus submission), and produce eight: domineering/controlling, vindictive/self-centered, cold/distant, avoidant/socially inhibited, nonassertive/obsequious, exploitable/overly accommodating, over-nurturant/self-sacrificing and intrusive/needy (Fig. 1).[14] The only study, conducted by Seo et al., showed that interpersonal problems and internet addiction were significantly correlated [15], especially the types of interpersonal sensitivity, asocial behavior, nonassertiveness, criticize/distrust, and overnurturance. Interpersonal problems are related to loneliness, especially socially inhibited style.[16] An assumption regarding the relationship on internet addiction was that socially inhibited individuals, also seen as introverted, may use the internet to connect with individuals instead of interacting in real situations. [17-19] For shy individuals, instant messaging (included in social networking such as Facebook) may be used to reduce their loneliness.[20] Moreover, some people with hostile (unfriendly) interpersonal style may use internet addiction as a coping mechanism. [21] A narcissistic person (hostile-dominant) could exhibit a unique way regarding pathological use of the internet as well.[22]

As we have already known, the cause of internet addiction is rather complex.[23]. As shown by the aforementioned documents, one study revealed that people with internet addiction tended to showed high motivation for anonymity, simplified communication, emotional support, social compensation and escapism[24], particularly motivation for escapism was predominantly found in online gaming[25]. Some investigators viewed the use of the internet as a form of displacement activity, e.g., when there is nothing else to do or when the task one was handling was unappealing.[15, 26] Motivation for the internet use should; therefore, be considered as it determines activities-related to the internet. Researchers have found that excessive internet users are engaged in specific activities rather than 'generalized' use. Activities related to internet addiction were mostly nonwork online such as accessing general information and news, social networking and using e-mail and/or online chatting.[22, 27-30]

Despite the fact that significant relationship loneliness or interpersonal problems and internet addiction have been identified, the test of their relationship in a mediation model is lacking. More importantly, motivation to access the internet may be related to the existing interpersonal problems one has. For example, 
domineering individuals, experiencing loneliness, may respond to their feelings using a different activity related to the internet from those who are socially inhibited. However, how each type of interpersonal problem influenced loneliness, motivation of the internet use and internet addiction is little known.

The present study aimed to test, to the best of our knowledge, for the first time, the relationships among loneliness, a variety of interpersonal problems and internet addiction symptoms. The conceptual model configures the investigated variables in a mediation model. Each of eight subscales of interpersonal problems was examined separately within the prospective models. We hypothesized that all interpersonal subscales would be significant mediators but differ in magnitude for the indirect effect of loneliness concerning internet addiction. As we believe that the motivation of internet use may be influenced by specific type of interpersonal problems, we then tested using a serial mediation model by which each motivation was included as the second mediator. We hypothesized that a significant indirect effect may help understand these specific relationships among four variables at a deeper level. Finally, various types of motivation of internet use were tested for interaction with interpersonal problem subscales in a moderated mediation model, hypothesizing that some variables may require interaction to take effect.

\section{Methods \\ Participants and procedures}

This study was conducted at the Faculty of Medicine, Chiang Mai University, Chiang Mai, Thailand. Data were collected cross-sectionally with 318 medical students using convenience sampling. Each participant completed the questionnaires consisting of: 1) demographic data, 2) items concerning motivation of internet use, 2) the internet addiction test, 3) the questionnaires assessing loneliness and 4) the questionnaires assessing the interpersonal problems.

\section{Measures}

1. Questionnaires were used to investigate motivation or objectives of internet use. The first questionnaire consisted of 24 items concerning respondent's motivation of using the internet, asking how much the respondents agreed to respective objectives using a 5-point scale, ranging from 1 (strongly disagree) to 5 (strongly agree).

2. The IAT, developed by Young [31], is a 20-item self-report instrument in which respondents rate the tendency for addiction to the internet using a 5-point scale, ranging from 1 (rarely) to 5 (always). Total score yields only an estimate of the overall severity of internet addiction. Higher scores indicate greater addiction. The Thai version was developed by Wongpakaran N. et al.[32] The study sample received a Cronbach's alpha of 0.90 .

3. The 6-item Revised UCLA Loneliness Scale (RULS-6) is a short form of the revised UCLA Loneliness scale.[33, 34] Using this self-report instrument respondents rate the severity of a wide range of feelings of loneliness using a 4-point scale, ranging from 1 (never) to 4 (often). Higher scores indicate greater feelings of loneliness. The RULS- 6 demonstrated strong internal consistency (Cronbach's alpha $=0.72$ to 0.84 ); and the scale performed acceptably with this study's sample (Cronbach's alpha $=0.79$ ).

4. The IIP-32, developed by Horowitz et al.[35], includes 32 questions comprising 8 different interpersonal problems: domineering/controlling (D0), vindictive/self-centered ( $\mathrm{VI}$ ), cold/distant (CO), socially inhibited (SI), nonassertive (NO), overly accommodating (OA), self-sacrificing (SS) and intrusive/needy (IN). It uses a self-report instrument in which respondents rate the severity of a wide range of interpersonal problems using a 5-point scale, ranging from 1 (not at all) to 5 (extremely). Each subscale has four items. Higher scores denote greater interpersonal difficulties. The IIP-32 demonstrated strong internal consistency (Cronbach's alpha $=0.84$ ) and acceptable test-retest reliability (intraclass correlation coefficient $=0.74)$. The Thai version demonstrated excellent reliability and validity.[36] The scale performed well with this study's sample (Cronbach's alpha $=0.88$ ).

\section{Statistical analysis}

Descriptive analysis was carried out using socio-demographic, internet-related and all clinical variables by frequency, percentage, and mean standard deviation. Data reduction method was applied for the questionnaires concerning objectives and activities involving the internet using principal component analysis.

Bivariate correlations between motivation for internet use, loneliness, eight subscales of interpersonal problems and internet addiction were performed. Analyses were conducted using SPSS, Version 22.

We treated loneliness, eight subscales of interpersonal problems and internet addiction as latent variables. Each of the eight interpersonal subscales was represented in the model by its four observed variables. For the structural equation model, three parcels for the IAT were created. We created parcels for the internet addiction test variables according to loading coefficients by determining them to be parcels 1, 2 and 3 according to loading coefficients. Before testing the structural model, we tested the measurement model and assessed the parcel and subscale loadings on latent constructs. The model fit was assessed using standard $\chi 2$ fit statistics, the comparative fit index (CFI), the Tucker-Lewis Index (TLI) and the root mean square error of approximation (RMSEA). A CFI and TLI greater than 0.95 and a RMSEA less than 0.08 indicated a good model fit.[37] Because $\chi 2$ statistics is sensitive to sample size, we used the ratio of $\chi 2$ to degrees of freedom $(\chi 2 / d f)$ to assess model fit. $A(\chi 2 / d f)$ ratio of less than 3 indicated an acceptable model fit. Modifications to the initial hypotheses were performed to calculate the modification indices. When the proposed modifications were considered acceptable from a theoretical viewpoint, a new model was elaborated and analyzed. Correlated errors were allowed only within its measurement model to provide the model that best fit the data.

Tests of mediation were examined using two steps. In the mediation model, we used latent variables of IIP, RULS-6 and IAT for the first model (Fig. 2), and then we tested each IIP subscale mediator. Bootstrapping denotes repeatedly sampling from the data set and estimates the indirect effect in each resampled data set. It provides a more reliable confidence interval $(\mathrm{Cl})$ for mediation effect under most conditions; thus, it was used to ensure the mediation effect. The biascorrected and accelerated $95 \% \mathrm{Cl}(\mathrm{BCa} 95 \% \mathrm{Cl})$ of the medication effect method was used, significance effect was determined when the estimated coefficients 
excluded 0. The bootstrap estimate employed in the present study was based upon 5,000 bootstrap samples.[38] All path coefficients were reported in standardized format. AMOS version 18 was used for this analysis.

Serial mediation and moderated mediation were proposed by adding motivation for internet use in the mediation model. Motivation was treated as the second mediator (serial mediation model) or as the moderator of IIP subscale (moderated mediation model). Given that we proposed a serial mediation model, we constructed possible models in which eight interpersonal problems precedes motivation of internet use to determine the importance of variable order (Fig. 3). At the same token, we proposed a moderated mediation, by which each interpersonal problem was moderated by the specific motivation of internet use (Fig. 4). Because latent variables were used instead of observed variables, the latent mediation structural equation model was applied. The percent of variances explained the IAT score that was calculated using R square change to compare between models. Sample size estimation required the desired statistical power level of 0.8 , anticipated effect size of 0.3 , number of latent variables of 4 , and number of observed variables of 18 (including age and sex) was 137 at minimum while this study used 324[39].

Mplus, Version 8.5[40] with the XWITH command using full information maximum likelihood with robust standard errors was used to assess the latent moderated structural equations model.

\section{Ethics}

The study procedures were carried out in accordance with the Declaration of Helsinki. The Institutional Review Board of the Faculty of Medicine, Chiang Mai University approved the study. All subjects were informed about the study and all provided informed consent.

\section{Results}

\section{Preliminary analyses}

Table 1 shows the mean age of subjects was 20.88 (SD 1.8), and $56.8 \%$ were female. The average time using the internet was 4.9 hours (SD $=2.7)$, min-max $=$ $1-20$, median $=4.0$ hours. The internet addiction level according to Young's score was $119(36.7 \%)$, comprising mild, $30.9 \%$, moderate, 5.2\% and 0.6\%.

Principal component analysis reduced 24 motivation types of internet use to eight factors, including 1 ) negative intention, i.e., avoiding real life problems, creating an imaginary self and giving negative feedback or making disparaging remarks, and confronting without negative social consequences); 2) being accepted, i.e., belonging to a group, being recognized and acceptance/praise, 3) taking pleasure, i.e., checking other's status, recreation and leisure, 4) working, i.e., web board, writing blog/online diary, online banking/business online and shopping/online auction; 5) entertainment, i.e., movies/music, downloading movies, music and YouTube; 6) social connection, i.e., chat and Facebook/Twitter; 7) studying, i.e., Google search, email and e-learning and 8) indulgence, i.e., online games and gambling. 
Table 1

Mean and SD of sociodemographic, motivation of internet use, and interpersonal problems

\begin{tabular}{|c|c|c|c|c|}
\hline & Minimum & Maximum & Mean & Std. Deviation \\
\hline Age & 18 & 24 & 20.85 & 1.80 \\
\hline internet addiction total score & 5 & 85 & 28.18 & 12.73 \\
\hline RULS-6 & 6 & 24 & 12.36 & 3.54 \\
\hline \multicolumn{5}{|l|}{ IIP subscale } \\
\hline Domineering & 0 & 12 & 4.49 & 2.74 \\
\hline Vindictive & 0 & 11 & 3.68 & 2.44 \\
\hline Cold & 0 & 12 & 4.28 & 2.88 \\
\hline Socially inhibited & 0 & 15 & 4.66 & 3.02 \\
\hline Nonassertive & 0 & 12 & 6.44 & 2.53 \\
\hline Overly accommodating & 0 & 14 & 6.59 & 2.71 \\
\hline Self-sacrificing & 0 & 13 & 6.24 & 2.78 \\
\hline Intrusive & 0 & 14 & 4.75 & 2.75 \\
\hline IIP total score & 2 & 83 & 41.29 & 13.52 \\
\hline \multicolumn{5}{|l|}{ Motivation of internet use } \\
\hline Negative intention & 4 & 16 & 6.06 & 2.41 \\
\hline Being accepted & 3 & 14 & 6.92 & 2.59 \\
\hline Taking pleasure & 6 & 15 & 12.11 & 1.87 \\
\hline Working & 4 & 16 & 6.06 & 2.41 \\
\hline Entertainment & 3 & 14 & 6.92 & 2.59 \\
\hline Social connection & 6 & 15 & 12.11 & 1.87 \\
\hline Studying & 4 & 15 & 6.83 & 2.37 \\
\hline Indulgence & 4 & 15 & 11.06 & 2.19 \\
\hline
\end{tabular}

As seen in Table 2, RULS-6 score and all subscales of interpersonal problems had significant relationship with IAT score (all ps <.01), except for intrusive subscale. The domineering subscale did not exhibit a significant relationship with nonassertive and overly accommodating subscales, whereas vindictive did not show a significant relationship with self-sacrifice and intrusive subscales, which overall was compatible with the interpersonal circumplex in that they are on the opposite character. All these subscales were treated as an independent trait for the structural equation model. Age was significantly correlated with working online, social connection and indulgence; whereas sex was significantly correlated between entertaining, studying and indulgence. Different interpersonal subscales were associated with different internet activities. For example, domineering and intrusive subscales were significantly related to negative intention, being accepted and working. The remaining details are shown in Table 2. 
Table 2

Zero-order correlation between variables

\begin{tabular}{|c|c|c|c|c|c|c|c|c|c|c|c|c|}
\hline & & 1 & 2 & 3 & 4 & 5 & 6 & 7 & 8 & 9 & 10 & 11 \\
\hline 1 & Age & & & & & & & & & & & \\
\hline 2 & Sex & 0.07 & & & & & & & & & & \\
\hline 3 & IAT & -0.03 & 0.04 & & & & & & & & & \\
\hline 4 & RULS-6 & -0.07 & -0.07 & $.292^{\star \star}$ & & & & & & & & \\
\hline 5 & DO & -0.02 & -0.06 & $.254^{\star \star}$ & $.222^{\star \star}$ & & & & & & & \\
\hline 6 & $\mathrm{VI}$ & 0.03 & -0.04 & $.267^{\star \star}$ & $.412^{\star \star}$ & $.265^{\star \star}$ & & & & & & \\
\hline 7 & $\mathrm{CO}$ & -0.08 & -0.08 & $.246^{\star \star}$ & $.567^{\star \star}$ & $.172^{\star \star}$ & $.592^{\star \star}$ & & & & & \\
\hline 8 & SI & -0.04 & $-.135^{\star}$ & $.281^{\star \star}$ & $.619 * \star$ & $.140 *$ & $.544^{\star \star}$ & $.692^{\star \star}$ & & & & \\
\hline 9 & NO & -0.07 & -0.03 & $.210 \star \star$ & $.331^{\star \star}$ & 0.05 & $.337 \star \star$ & $.446 \star *$ & $.457^{\star *}$ & & & \\
\hline 10 & $\mathrm{OA}$ & -0.06 & -0.03 & $.199 * \star$ & $.335^{\star \star}$ & 0.01 & $.189 * \star$ & $.404^{\star \star}$ & $.407^{\star \star}$ & $.642^{\star \star}$ & & \\
\hline 11 & SS & -0.06 & 0.02 & $.309 * \star$ & $.264^{\star \star}$ & $.282^{\star \star}$ & 0.03 & $.216^{\star \star}$ & $.217^{\star \star *}$ & $.327^{\star \star}$ & $.589 * \star$ & \\
\hline 12 & IN & 0.04 & 0.10 & $.249 \star \star$ & 0.08 & $.524 \star \star$ & 0.11 & 0.03 & -0.02 & $.188^{\star \star}$ & $.176^{\star \star}$ & $.413^{\star *}$ \\
\hline \multicolumn{13}{|c|}{ Note: } \\
\hline
\end{tabular}

\section{Testing for mediation effect}

All measurement models were tested separately and all models were found to indicate good fit statistics. The first aim of this study was to investigate whether IIP would mediate the relationship between loneliness and internet addiction (Fig. 2).

Table 3 shows that both the direct and the indirect effects of the eight IIP subscales on IAT were significant, except for IN (as IN had no correlation with RULS6) and $\mathrm{CO}$, which had no significant indirect effect. According to MacKinnon's concept, IN was not considered a mediator. Fit statistics showed that all models fit the sample well.

Table 3

Total, direct, and indirect effects of RULS-6 and IIP subscale on IAT controlling for age and sex

\begin{tabular}{|c|c|c|c|c|c|c|c|c|c|c|c|c|c|c|c|c|}
\hline $\begin{array}{l}\text { Mediator } \\
\text { (IIP } \\
\text { subscale) }\end{array}$ & $\begin{array}{l}\text { Total } \\
\text { effect } \\
\text { RULS- } \\
6 \diamond \\
\text { IAT }\end{array}$ & $\begin{array}{l}\mathrm{p}- \\
\text { value }\end{array}$ & $\begin{array}{l}\text { Direct } \\
\text { effect of } \\
\text { RULS-6 } \diamond \\
\text { mediator(a) }\end{array}$ & $\begin{array}{l}\mathrm{p}- \\
\text { value }\end{array}$ & $\begin{array}{l}\text { Direct } \\
\text { effect } \\
\text { of } \\
\text { RULS- } \\
6 \diamond \\
\text { IAT } \\
\text { (c') }\end{array}$ & $\begin{array}{l}\mathrm{p}- \\
\text { value }\end{array}$ & $\begin{array}{l}\text { Direct } \\
\text { effect of } \\
\text { mediator } \\
\diamond \text { IAT(b) }\end{array}$ & $\begin{array}{l}\mathrm{p}- \\
\text { value }\end{array}$ & $\begin{array}{l}\text { Indirect } \\
\text { effect } \\
(a * b)\end{array}$ & $\begin{array}{l}\text { p- } \\
\text { value }\end{array}$ & $x^{2}$ & df & $\begin{array}{l}\chi^{2} \\
/ d f\end{array}$ & $\mathrm{CFI}$ & TLI & RM \\
\hline DO & .315 & .000 & .323 & .000 & .240 & .001 & .233 & .002 & .075 & .001 & 82.0 & 70 & 1.17 & .991 & .988 & .02 \\
\hline VI & .312 & .000 & .414 & .000 & .203 & .005 & .263 & .001 & .109 & .001 & 130.1 & 71 & 1.83 & .959 & .947 & .05 \\
\hline $\mathrm{CO}$ & .314 & .000 & .610 & .000 & .238 & .010 & .125 & .161 & .076 & .148 & 131.8 & 71 & 1.86 & .959 & .948 & .05 \\
\hline SI & .327 & .000 & .655 & .000 & .172 & .079 & .236 & .017 & .154 & .013 & 130.4 & 85 & 1.53 & .972 & .961 & .04 \\
\hline NO & .323 & .000 & .414 & .000 & .256 & .000 & .163 & .049 & .067 & .038 & 114.7 & 68 & 1.69 & .962 & .949 & .04 \\
\hline OA & .322 & .000 & .469 & .000 & .214 & .014 & .230 & .015 & .108 & .010 & 81.9 & 67 & 1.22 & .988 & .983 & .02 \\
\hline SS & .322 & .000 & .388 & .000 & .198 & .012 & .319 & .000 & .124 & .000 & 101.0 & 68 & 1.48 & .975 & .967 & .03 \\
\hline IN & .323 & .000 & .056 & .421 & .308 & .000 & .263 & .001 & .015 & .375 & 119.1 & 67 & 1.78 & .961 & .947 & .04 \\
\hline
\end{tabular}

Note: IIP = inventory of interpersonal problems, $\mathrm{DO}=$ domineering/controlling, $\mathrm{VI}=$ vindictive, $\mathrm{CO}=$ cold, $\mathrm{SI}=$ socially inhibited, $\mathrm{NO}=$ nonassertive, $\mathrm{OA}=\mathrm{overly}$ accommodating, $\mathrm{SS}=$ self-sacrificing, IN = intrusive, $\chi^{2}=$ Chi-square, $\mathrm{df}=$ degree of freedom, $\mathrm{CFI}=$ comparative fit index, TLI = Tucker-Lewis Index, RMSEA = Ro square error of approximation, RULS- $6=6$-item revised UCLA loneliness scale, IAT $=$ internet addiction test

Among all eight mediators, SI appeared to exhibit the highest effect size of mediation effect because its direct effect on IAT (c') was reduced to nonsignificant $(p=.079)$.

The results showed that six dimensions of IIP served as mediators, from partial or full, for loneliness concerning internet addiction, despite the fact that they differed in style or were even opposite such as DO and NO. Subsequently, each of the motivation types for internet use was included in the mediation models 
creating serial mediation analysis (Fig. 3), and each motivation of the internet was used a moderator of the IIP subscale to create moderated mediation analysis (Fig. 4). Altogether, 128 (64 serial mediation +64 moderated mediation) models were tested individually.

Among all 64 serial mediation, structural equation models, only 12 models, in which Mediator 1 were DO, CO, VI, SI, OA, IN and Mediator 2 were accepted; negative intention and working had a significant indirect effect on IAT ( $\beta=0.057$ to -0.123 , all $p s<.05)$. None of any significant indirect models was found in SS and NO (Table 4). The fit statistics revealed that all models fit the sample well.

Table 4

Results of the serial mediation models controlling for age and sex (only significant indirect effects)

\begin{tabular}{|c|c|c|c|}
\hline Mediator (M1) & Mediator (M2) & Indirect effect of RULS-6 $\Delta$ IAT through M1and M2 : $\beta$ (SE) & p-value \\
\hline \multirow[t]{3}{*}{ DO } & Being accepted & $0.113(0.043)$ & 0.009 \\
\hline & Negative intention & $0.397(0.070)$ & 0.000 \\
\hline & Working online & $0.071(0.035)$ & 0.038 \\
\hline \multirow[t]{2}{*}{$\mathrm{CO}$} & Being accepted & $0.219(0.072)$ & 0.002 \\
\hline & Negative intention & $0.357(0.085)$ & 0.000 \\
\hline \multirow[t]{4}{*}{$\mathrm{VI}$} & Being accepted & $0.190(0.051)$ & 0.000 \\
\hline & Negative intention & $0.393(0.071)$ & 0.000 \\
\hline & Working online & $0.112(0.040)$ & 0.005 \\
\hline & Studying & $0.089(0.044)$ & 0.045 \\
\hline \multirow[t]{6}{*}{$\mathrm{SI}$} & Being accepted & $0.310(0.070)$ & 0.000 \\
\hline & Negative intention & $0.470(0.093)$ & 0.000 \\
\hline & Working online & $0.175(0.057)$ & 0.002 \\
\hline & Studying & $0.147(0.062)$ & 0.017 \\
\hline & Indulgence & $0.176(0.079)$ & 0.025 \\
\hline & Social connection & $0.152(0.075)$ & 0.042 \\
\hline \multirow[t]{4}{*}{ SS } & Being accepted & $0.168(0.046)$ & 0.000 \\
\hline & Negative intention & $0.427(0.076)$ & 0.000 \\
\hline & Working online & $0.118(0.040)$ & 0.003 \\
\hline & Studying & $0.099(0.042)$ & 0.019 \\
\hline \multirow[t]{3}{*}{ NO } & Being accepted & $0.132(0.045)$ & 0.003 \\
\hline & Negative intention & $0.383(0.077)$ & 0.000 \\
\hline & Working online & $0.095(0.041)$ & 0.019 \\
\hline \multirow[t]{3}{*}{ OA } & Being accepted & $0.157(0.050)$ & 0.002 \\
\hline & Negative intention & $0.373(0.076)$ & 0.000 \\
\hline & Working online & $0.112(0.048)$ & 0.021 \\
\hline \multirow[t]{2}{*}{ IN } & Being accepted & $0.087(0.041)$ & 0.036 \\
\hline & Negative intention & $0.348(0.070)$ & 0.000 \\
\hline \multicolumn{4}{|c|}{$\begin{array}{l}\beta=\text { standardized estimate, } S E=\text { standard error, } \mathrm{DO}=\text { domineering, } \mathrm{VI}=\text { vindictive, } \mathrm{CO}=\text { cold } / \text { distant } \mathrm{SI}=\text { socially inhibited, } \mathrm{NO}=\text { nonassertive, } \mathrm{OA}=\text { overly } \\
\text { accommodating } \mathrm{SS}=\text { self-sacrificing, } \mathrm{IN}=\text { intrusive, } \mathrm{RULS}-6=6 \text {-item revised UCLA loneliness scale, } \mathrm{IAT}=\text { internet addiction test }\end{array}$} \\
\hline
\end{tabular}

When latent variables of motivation interacted with the IIP subscale, the motivation of negative intention and being accepted mediated all eight of the IIP subscales. Motivation of working online mediated all interpersonal problems, except for CO and IN. Notably, IN had no mediation effect but when combined with negative intention, it produced the effect of IN and negative intention. For SI, all activities but social connection became the second mediators and produced significant indirect effect concerning loneliness to internet addiction (Table 4).

Table 5 shows significant moderators of motivation and total indirect effects of IIP subscales. DO and IN were not moderated by any motivation. Among all 64 interacted latent variables, only negative intention moderated VI, and working moderated SI, NO, OA and SS. In addition, a significant indirect effect of these IIP subscales was found through the moderators with $t=2.745, p=.0006 ; t 2.869, p=0.004 ; t=2.499, p=0.012 ; t=2.498, p=0.012$ and $t=2.528 p=0.011$, respectively. 
Table 5

Results of the latent moderated mediation controlling for age and sex (only significant total indirect effects)

\begin{tabular}{|c|c|c|c|c|c|c|c|}
\hline $\begin{array}{l}\text { Mediator } \\
\text { (M1) }\end{array}$ & Moderator (M2) & Interaction effect of $M 1$ and $M 2$ on IAT : $\beta$ (SE) & $t$ & $\begin{array}{l}\mathrm{p}- \\
\text { value }\end{array}$ & Total Indirect effect : $\beta$ (SE) & $t$ & p-value \\
\hline DO & - & - & - & - & - & - & - \\
\hline $\mathrm{VI}$ & $\begin{array}{l}\text { Negative } \\
\text { intention }\end{array}$ & $0.178(0.084)$ & 2.129 & 0.033 & $0.132(0.048)$ & 2.745 & 0.006 \\
\hline $\mathrm{CO}$ & - & - & - & - & & & \\
\hline $\mathrm{SI}$ & Working & $0.278(0.089)$ & 3.138 & 0.002 & $0.286(0.100)$ & 2.869 & 0.004 \\
\hline NO & Working & $0.294(0.118)$ & 2.493 & 0.013 & $0.229(0.092)$ & 2.499 & 0.012 \\
\hline $\mathrm{OA}$ & Working & $0.263(0.080)$ & 3.304 & 0.001 & $0.218(0.087)$ & 2.498 & 0.012 \\
\hline SS & Working & $0.250(0.115)$ & 2.176 & 0.030 & $0.249(.099)$ & 2.528 & 0.011 \\
\hline IN & - & - & - & - & - & - & - \\
\hline
\end{tabular}

In terms of R square change, the variance of IAT explained by all variables in the mediation model (one mediator of interpersonal problems) was approximately $13 \%$, and increased to approximately $43 \%$ for the serial mediation model (two mediators), and to approximately $33 \%$ for the moderated mediation model (one mediator of interpersonal problems, one moderator).

\section{Discussion}

This study aimed to examine how loneliness associated with internet addiction using interpersonal problems as mediators. It became evident that interpersonal problem served as a mediator for loneliness and internet addiction. Motivation for internet use contributed to increased variances explained by internet addiction, denoting their significant effect on the relationship between loneliness and interpersonal problems, and internet addiction.

Socially inhibited problem was the strongest mediator among all, showing full mediation, denoting that the association between loneliness and internet addiction might be nonsignificant when the socially inhibited interpersonal problems was removed. This finding was endorsed by Horowitz and French[41] in that lonely individuals consistently reported problems of inhibited sociability. The remaining interpersonal problems produced a mediation effect, but exhibited a partial effect, except for intrusive/needy, which had no mediation effect.

The study aimed to understand why different interpersonal problems, even on the opposite quadrant, had the same effect on internet addiction. As hypothesized, specific motivation for internet use related to some interpersonal problems and resulted in an effect on internet addiction. The motivation of being accepted and of negative intention were found to be the second mediator for all models, regardless of interpersonal problems. This is reasonable for any user to use the internet to be accepted. In a word, regardless of the type of interpersonal problems an individual has, desire to be accepted and to receive social support is common.[42-44] On the contrary, negative intention including defamatory remarks, bullying others was associated with all types of interpersonal problems because being an anonymous user provided an opportunity to do so.

Negative intention may not be that surprising when it occurs along a hostile axis of interpersonal problems such as the vindictive subscale, but what could be the explanation considering the friendly style such as overly accommodating? Recall that interpersonal problems do not constitute a cognitive style[45] as even the friendly interpersonal style could express negative thoughts. Investigators have revealed that overly accommodating significantly correlated with fantasy proneness, irresponsibility and negative affect, which was endorsed in the negative intention factor found in the present study.[46] In other words, participants with loneliness may be likely to become internet addicts when they had negative thoughts and negative intention (feelings that bring out the worst in them), because the internet could be the network where they can safely express their denigration, which is difficult to do so in real life.

Notably, SI was the only IIP subscale that related to various types of motivation either positive or negative aspect. A motivation for social connection such as chatting, using Facebook or Twitter, and searching the internet may not differentiate addicted individuals from normal users, and did not affect internet addiction score.[30] However, SI became one of the important variables associated between loneliness and internet addiction. It may reflect that people who are socially inhibited tend to access the internet much more with a variety of motivations, particular in escapism using online gaming[47].

Another point is that IN was not a mediator in the first place but could become one when the motivation variables were added. This highlights the importance of unobserved variables like motivation to be accepted or to express negative feeling on internet addiction that may prevail over any particular type of interpersonal problem.

Interestingly, motivation for working online became both a mediator and a moderator in some types of IIP. Regarding mediation effect, it may be unsurprising that working served as an additional effect on the model but in the moderating model, working become a moderator only with submissive style of IIP, i.e., SI, NO, OA and SS, meaning that these IIP subscales differentially predicted internet addiction as a function of working online. To put in other words, at medium to high levels of working online, the magnitude of correlations (slope) between them was significantly greater than at lower level (sharper slope). This could provide us some insight that those with submissive character, when they feel lonely and keep a high level of working online, tend to become addicted to the 
internet. Another moderation effect was found in VI and negative intention, indicating that the higher the level of negative intention, the more the predicting of VI concerning internet addiction could be observed.

Overall, we have attempted to determine what makes each pair of IIP subscales and loneliness differ concerning internet addiction. They all involve and are also determined by the motivation of internet use. Despite the fact that motivation of the users sheds some light on the link between loneliness, interpersonal problem and internet addiction, more models remain untested, which might yield a better fit and understanding of clinical data, for example, moderation between motivation and loneliness concerning IIP and moderation between motivation and loneliness concerning IAT. Further investigation should be warranted.

\section{Strengths and limitations}

This may constitute the first analysis regarding a mediation model of loneliness and interpersonal problems concerning internet addiction. Moreover, including motivation types in the structural model was accomplished for the first time to explain the difference between the effects each interpersonal problem has on internet addiction score, for which the summary findings presented were derived from overall extensive analyses of 136 models. However, our study had some limitations. First, this study was confined to a medical student population and might not be generalized to the general population. A replication study in other populations is encouraged. Second, depression was excluded, which may be linked to loneliness (or interpersonal problems). This may have made it difficult to conclude that interpersonal problems were the only mediator for loneliness despite the fact that depression might have also contributed. Moreover, a separate analysis based on type of internet addiction may be useful to obtain more insights concerning the varied nature of addiction among users.

\section{Conclusion}

Our findings may add more knowledge about why and how loneliness is related to internet addiction. Loneliness alone may not sufficiently explain internet addiction consisting of a variety of activities related to both motivation of using the internet and interpersonal problems the users possess. Specific type of interpersonal problem combined or interacting with the motivation for the internet use evidently becomes an important factor in increased contribution to the prediction of internet addiction. A replication study especially in other populations should be warranted.

\section{Abbreviations}

\section{IIP}

Inventory of Interpersonal problems

\section{RULS-6}

The 6-item of the revised University of California Los Angeles Loneliness Scale

IAT

Internet addiction test

DO

Domineering

VI

Vindictive

CO

Cold

SI

Socially inhibited

NO

Nonassertive

OA

Overly accommodating

SS

Self-sacrificing

IN

Intrusive

\section{Declarations}

\section{Acknowledgements}

The authors wish to thank all the participants who participate in the study.

\section{Authors' contributions}

NW, TW, MP, SS, and PK participated in the concept and design of the study. SS and PK collected data. NW and TW performed the statistical analyses. NW, TW, MP, SS, and PK drafted and edited the manuscript. All authors made substantial contributions to interpret data and revised the manuscript for important intellectual content. All authors read and approved the final manuscript. 
Funding

This study was a self-financed research.

Availability of data and materials

The datasets used and/or analyzed during the current study are available from the corresponding author on reasonable request.

\section{Ethics approval and consent to participate}

This study was approved by the research ethics committee of the Faculty of Medicine, Chiang Mai University. All patients provided written informed consent to the study,

\section{Consent for publication}

Consent for publication is not applicable.

\section{Competing interests}

Tinakon Wongpakaran is an editorial board member of BMC Psychiatry. All the authors declare that they have no competing interests.

\section{References}

1. Leigh-Hunt N, Bagguley D, Bash K, Turner V, Turnbull S, Valtorta N, Caan W: An overview of systematic reviews on the public health consequences of social isolation and loneliness. Public Health 2017, 152:157-171.

2. Pedrelli P, Feldman G, Vorono S, Fava M, Petersen T: Dysfunctional attitudes and perceived stress predict depressive symptoms severity following antidepressant treatment in patients with chronic depression. Psychiatry Res 2008, 161:302-308.

3. Ramírez M, Hernández R: Factor structure of the Perceived Stress Scale (PSS) in a sample from Mexico. Span J Psycho/ 2007, 10:199-206.

4. Koyuncu T, Unsal A, Arslantas D: Assessment of internet addiction and loneliness in secondary and high school students. J Pak Med Assoc 2014, 64:998-1002.

5. Nalwa K, Anand AP: Internet addiction in students: a cause of concern. Cyberpsychol Behav 2003, 6:653-656.

6. Cerclé A, Gadéa C, Hartmann A, Lourel M: Typological and factor analysis of the perceived stress measure by using the PSS scale. European Review of Applied Psychology 2008, 58:227-239.

7. Huan VS, Ang RP, Chong WH, Chye S: The impact of shyness on problematic intemet use: the role of loneliness. J Psychol 2014, 148:699-715.

8. He F, Zhou Q, Li J, Cao R, Guan H: Effect of social support on depression of internet addicts and the mediating role of loneliness. Int J Ment Health Syst 2014, 8:34.

9. Li W, Zhang W, Xiao L, Nie J: The association of Internet addiction symptoms with impulsiveness, loneliness, novelty seeking and behavioral inhibition system among adults with attention-deficit/hyperactivity disorder (ADHD). Psychiatry Res 2016, 243:357-364.

10. Cho YR, Lee HJ: [A study on a model for internet addiction of adolescents]. Taehan Kanho Hakhoe Chi 2004, 34:541-551.

11. Lavin MJ, Yuen CN, Weinman M, Kozak K: Internet dependence in the collegiate population: the role of shyness. Cyberpsychol Behav 2004, 7:379-383.

12. Chak K, Leung L: Shyness and locus of control as predictors of internet addiction and internet use. Cyberpsychol Behav 2004, 7:559-570.

13. Kim E, Cho I, Kim EJ: Structural Equation Model of Smartphone Addiction Based on Adult Attachment Theory: Mediating Effects of Loneliness and Depression. Asian Nursing Research 2017, 11:92-97.

14. Alden LE, Wiggins JS, Pincus AL: Construction of circumplex scales for the Inventory of Interpersonal Problems. J Pers Assess 1990, 55:521-536.

15. Seo M, Kang HS, Yom YH: Internet addiction and interpersonal problems in korean adolescents. Comput Inform Nurs 2009, 27:226-233.

16. M. Horowitz L, de Sales French R: Interpersonal problems of people who describe themselves as lonely. 1979.

17. Zamani BE, Abedini Y, Kheradmand A: Internet Addiction Based on Personality Characteristics of High School Students in Kerman, Iran. Addiction \& Health 2011, 3:85-91.

18. McIntyre E, Wiener KKK, Saliba AJ: Compulsive Intemet use and relations between social connectedness, and introversion. Computers in Human Behavior 2015, 48:569-574.

19. van der Aa N, Overbeek G, Engels RCME, Scholte RHJ, Meerkerk G-J, Van den Eijnden RJJM: Daily and Compulsive Internet Use and Well-Being in Adolescence: A Diathesis-Stress Model Based on Big Five Personality Traits. Journal of Youth and Adolescence 2008, 38:765.

20. Bardi CA, Brady MF: Why shy people use instant messaging: Loneliness and other motives. Computers in Human Behavior 2010, 26:1722-1726.

21. Senormancı O, Konkan R, Güçlü O, Senormancı G: Depression, loneliness, anger behaviours and interpersonal relationship styles in male patients admitted to internet addiction outpatient clinic in Turkey. Psychiatr Danub 2014, 26:39-45.

22. Zerach G: Pathological narcissism, cyberbullying victimization and offending among homosexual and heterosexual participants in online dating websites. Computers in Human Behavior 2016, 57:292-299.

23. Marzilli E, Cerniglia L, Ballarotto G, Cimino S: Intemet Addiction among Young Adult University Students: The Complex Interplay between Family Functioning, Impulsivity, Depression, and Anxiety. International journal of environmental research and public health 2020, 17:8231. 
24. Eichenberg C, Schott M, Decker O, Sindelar B: Attachment Style and Intemet Addiction: An Online Survey. J Med Internet Res 2017, 19:e170.

25. Kuss DJ, Louws J, Wiers RW: Online gaming addiction? Motives predict addictive play behavior in massively multiplayer online role-playing games. Cyberpsychol Behav Soc Netw 2012, 15:480-485.

26. Hills P, Argyle M: Uses of the Internet and their relationships with individual differences in personality. Computers in Human Behavior 2003, 19:59-70.

27. Pontes HM, Szabo A, Griffiths MD: The impact of Internet-based specific activities on the perceptions of Internet addiction, quality of life, and excessive usage: A cross-sectional study. Addictive Behaviors Reports 2015, 1:19-25.

28. Upadhayay N, Guragain S: Internet use and its addiction level in medical students. Advances in Medical Education and Practice 2017, 8:641-647.

29. Ching SM, Hamidin A, Vasudevan R, Sazlyna MS, Wan Aliaa WS, Foo YL, Yee A, Hoo FK: Prevalence and factors associated with internet addiction among medical students - A cross-sectional study in Malaysia. Med J Malaysia 2017, 72:7-11.

30. Leung L, Lee PSN: Impact of Internet Literacy, Internet Addiction Symptoms, and Internet Activities on Academic Performance. Social Science Computer Review 2012, 30:403-418.

31. Young K: Internet addiction: The emergence of a new clinical disorder. CyberPsychology \& Behavior 1998, 1:237-244.

32. Neelapaijit A, Pinyopornpanish M, Simcharoen S, Kuntawong P, Wongpakaran N, Wongpakaran T: Psychometric properties of a Thai version intemet addiction test. BMC Res Notes 2018, 11:69.

33. Russell DW: UCLA Loneliness Scale (Version 3): reliability, validity, and factor structure. J Pers Assess 1996, 66:20-40.

34. Wongpakaran N, Wongpakaran T, Pinyopornpanish M, Simcharoen S, Suradom C, Varnado P, Kuntawong P: Development and validation of a 6-item Revised UCLA Loneliness Scale (RULS-6) using Rasch analysis. Br J Health Psychol 2020, 25:233-256.

35. Horowitz LM, Alden LE, Wiggins JS, Pincus AL: IIP inventory of interpersonal problems manual. Texas: the psychological corporation; 2000.

36. Wongpakaran T, Wongpakaran N, Sirithepthawee U, Pratoomsri W, Burapakajornpong N, Rangseekajee P, Bookkamana P, Temboonkiat A: Interpersonal problems among psychiatric outpatients and non-clinical samples. Singapore Med J 2012, 53:481-487.

37. Hu L, Bentler PM: Cutoff criteria for fit indexes in covariance structure analysis: conventional criteria versus new alternatives. Struct Equ Modeling $1999,6$.

38. Preacher KJ, Hayes AF: Asymptotic and resampling strategies for assessing and comparing indirect effects in multiple mediator models. Behavior Research Methods 2008, 40:879-891.

39. A-priori Sample Size Calculator for Structural Equation Models [Software] [A-priori Sample Size for Structural Equation Models References - Free Statistics Calculators (danielsoper.com)]

40. Muthén LK, Muthén BO: Mplus user's guide. Los Angeles, CA: Muthén; 2012.

41. Horowitz LM, de Sales French R: Interpersonal problems of people who describe themselves as lonely. Journal of Consulting and Clinical Psychology 1979, 47:762-764.

42. Canan F, Yildirim O, Sinani G, Ustunel TY, Yildirim M, Ozturk O, Ataoglu A: 999 - The self-image of adolescents and its relationship to internet addiction. European Psychiatry 2013, 28:1.

43. Aydm B, San SV: Internet addiction among adolescents: The role of self-esteem. Procedia - Social and Behavioral Sciences 2011, 15:3500-3505.

44. Ozcan NK, Buzlu S: Internet use and its relation with the psychosocial situation for a sample of university students. Cyberpsychol Behav 2007, 10:767772.

45. Meins E, McCarthy-Jones S, Fernyhough C, Lewis G, Bentall RP, Alloy LB: Assessing negative cognitive style: Development and validation of a Short-Form version of the Cognitive Style Questionnaire. Personality and Individual Differences 2012, 52:581-585.

46. Williams TF, Simms LJ: Personality Disorder Models and their Coverage of Interpersonal Problems. Personality disorders 2016, 7:15-27.

47. McInroy LB, Mishna F: Cyberbullying on Online Gaming Platforms for Children and Youth. Child and Adolescent Social Work Journal 2017, 34:597-607.

\section{Figures}




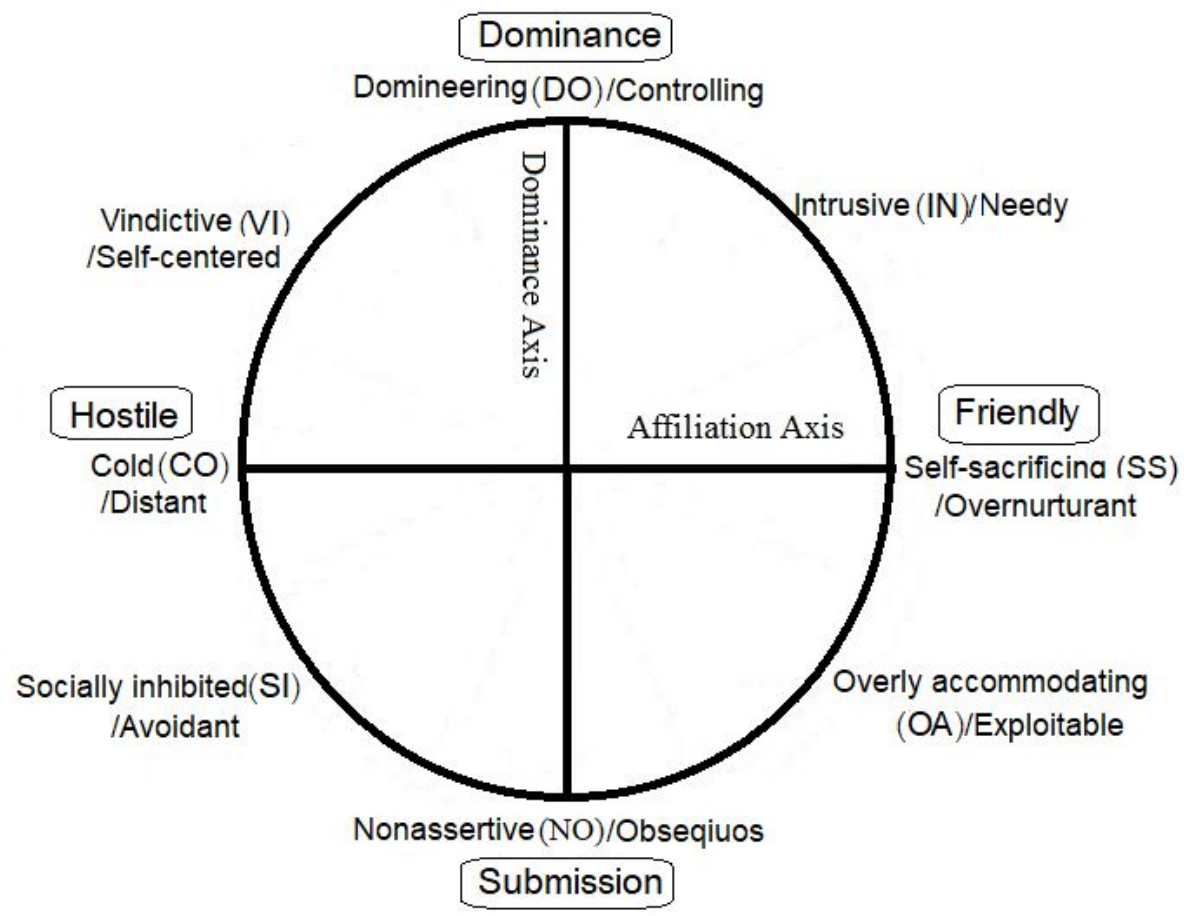

Figure 1

Interpersonal Circumplex

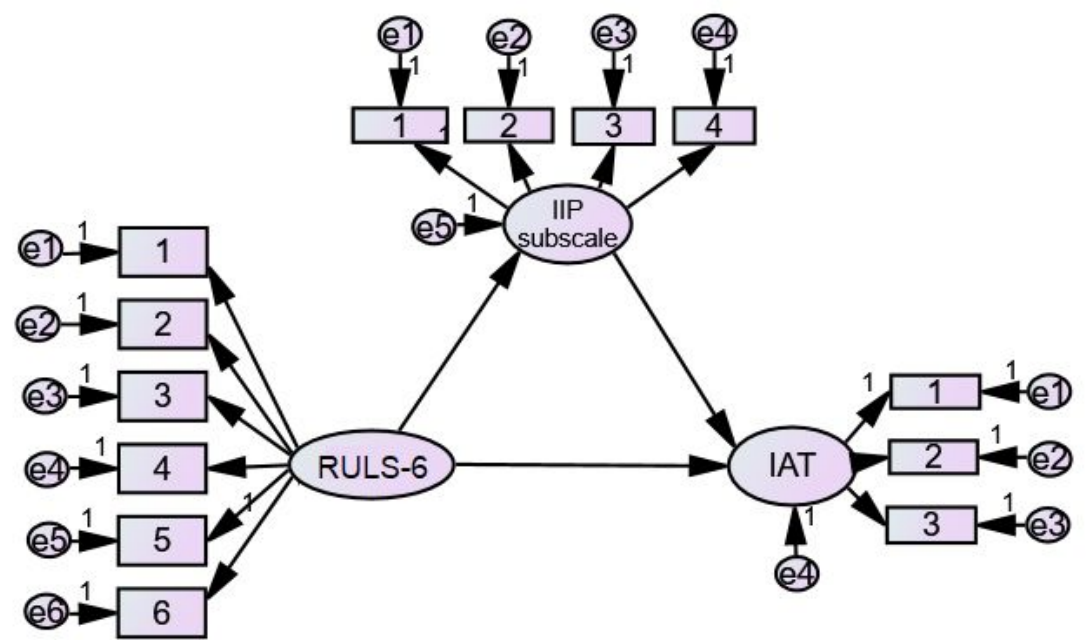

Figure 2

Mediation analysis with structural equation modeling Figure 1. Structural equation model for mediation (IIP as a latent mediator) IIP= inventory of interpersonal problems, RULS-6 = 6-item revised UCLA loneliness scale, IAT=internet addiction test 


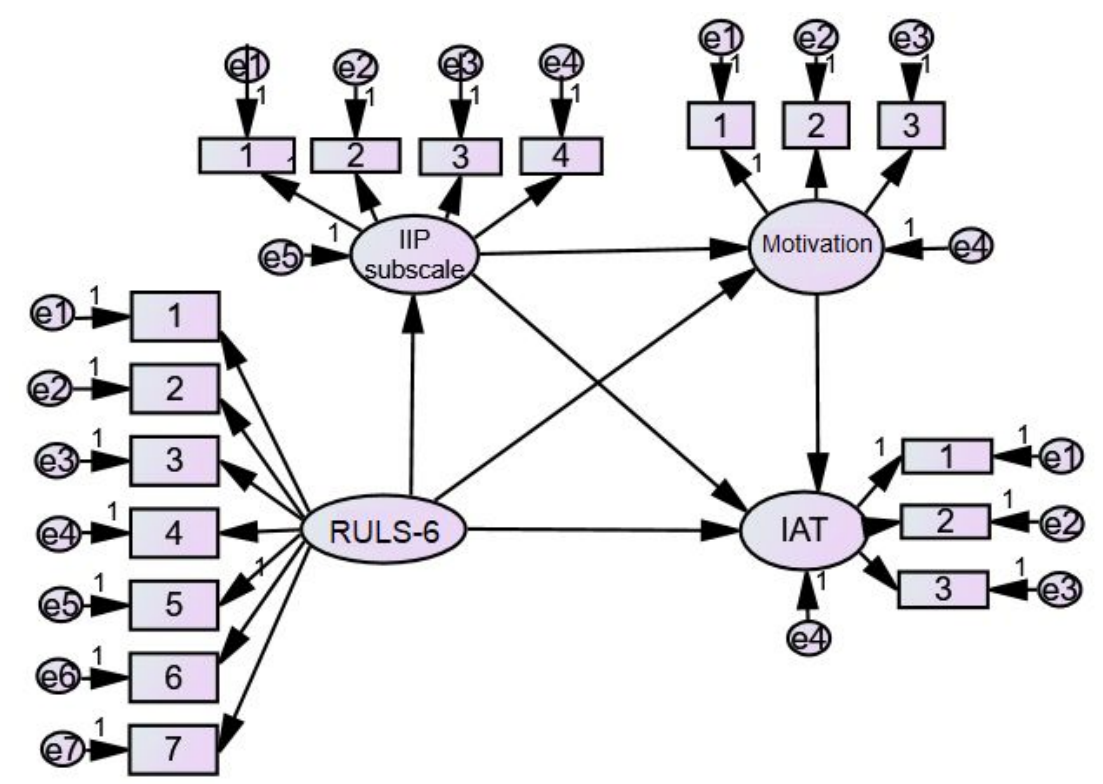

Figure 3

Structural equation model for serial mediation (two latent mediators) IIP= inventory of interpersonal problems, RULS-6 = 6-item revised UCLA loneliness scale, IAT=internet addiction test

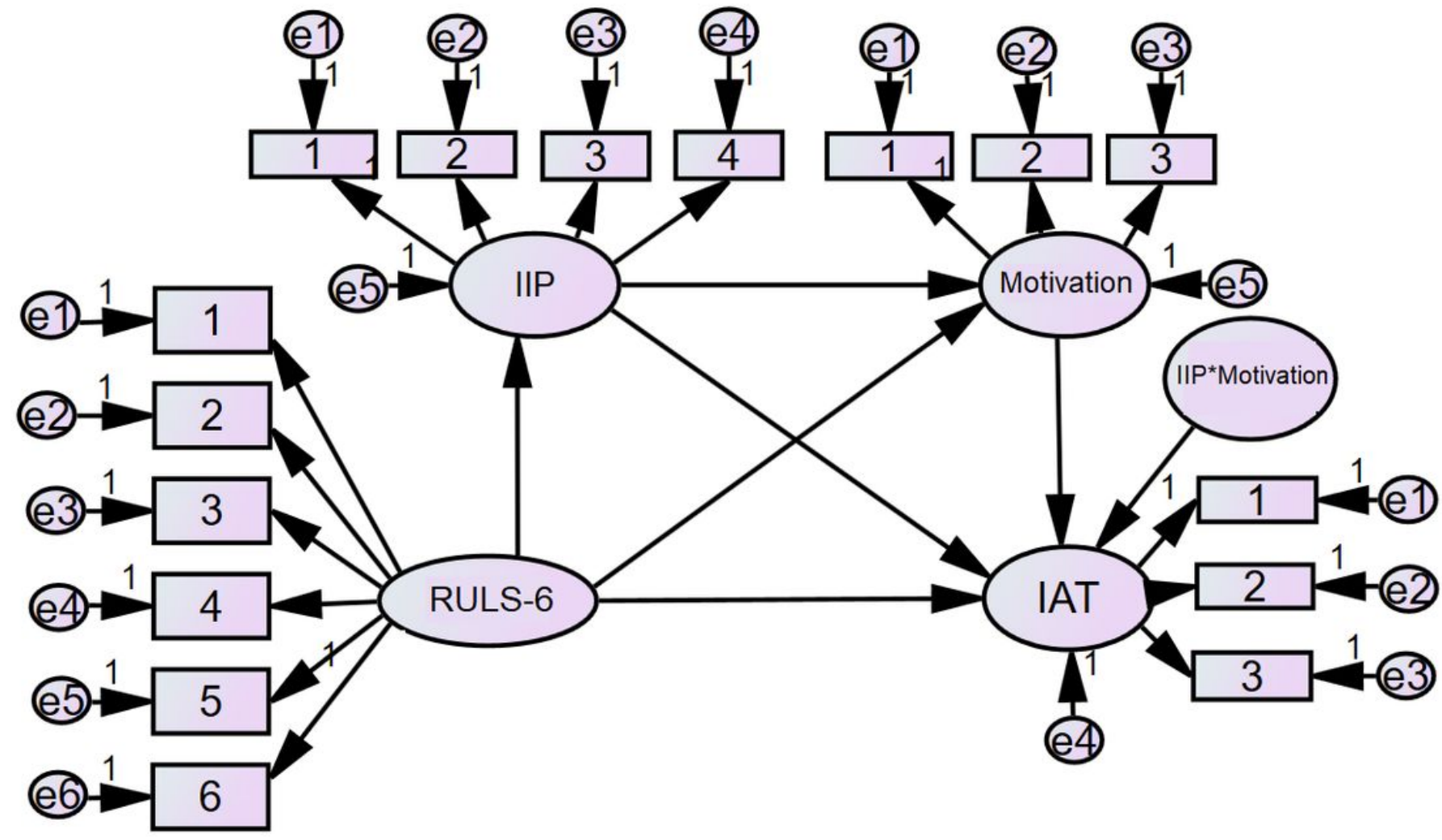

Figure 4

Structural equation model for latent moderated mediation IIP= inventory of interpersonal problems, RULS-6 = 6-item revised UCLA loneliness scale, IAT=internet addiction test 